\title{
Cross-level linkages in an ecology of climate change adaptation policy games
}

\author{
Matthew Hamilton ${ }^{1}$, Mark Lubell ${ }^{2}$ and Emilinah Namaganda ${ }^{3}$
}

\begin{abstract}
Social and ecological outcomes of environmental governance systems are shaped by interplay across the spatial levels at which policy actors and decision-making forums operate. We focus on the conditions under which actors participate in policy forums operating at higher or lower levels than the actors' own level. We draw upon theories of network science and transaction costs to formulate and test predictions about the overall prevalence of such cross-level linkages as well as the conditions under which policy actors engage in these linkages. We estimate an exponential random graph model using data collected from a survey of climate change adaptation policy actors participating in decision-making forums operating at different spatial levels within the Lake Victoria region in East Africa. Within this governance system, efforts to improve adaptive capacity across national boundaries and diverse vulnerable populations hinge on how well policy forums operating at regional and higher levels attract the participation of actors with access to information about local conditions, the efficiency with which actors can disseminate funding and technical resources through more local policy forums, as well as other processes that occur via cross-level linkages. We find that actors are less likely to engage in crosslevel linkages compared to within-level linkages. Conditioning on this general tendency, actors are even less likely to participate in forums operating at lower levels in which their collaborators also participate. By contrast, actors are more likely to participate in forums operating at lower levels when influential actors jointly participate. These findings, which highlight distinct roles of social and political capital in cross-level forum participation, have implications for efforts to improve climate change adaptation governance in the Lake Victoria region, as well as other multilevel governance systems.
\end{abstract}

Key Words: climate change adaptation; cross-level linkages; East Africa; exponential random graph models (ERGM); policy networks

\section{INTRODUCTION}

A hallmark of complex environmental governance systems is the complex interplay of actors and decision-making processes across different spatial levels (Young 2002, Brondizio et al. 2009, Lubell 2013). For example, in East Africa's Lake Victoria region, which provides the empirical setting for our research, hundreds of policy actors participate in the design and implementation of climate change adaptation measures under the auspices of multiple task forces, steering committees, and other policy forums in which actors regularly convene to collectively contribute to decisions about the design and implementation of policy (Ansell and Gash 2008, Fischer and Leifeld 2015). Collectively, these policy forums span multiple levels of geographic scale, from local to global. The aggregate impact of policy interventions designed to increase the adaptive capacity of vulnerable populations within the Lake Victoria region reflects patterns of interaction among these policy actors and forums. Although climate change adaptation is an archetypal multilevel problem (Termeer et al. 2010), the challenge of accounting for interactions that span spatial and administrative levels is ubiquitous in the field of environmental governance (Berkes 2002, Cash et al. 2006).

A core theme running throughout the environmental governance literature is that desirable outcomes such as sustainability and resilience not only hinge upon the performance of policy processes operating within each level of the overall governance system, but also on the integration of these processes across spatial levels (Brondizio et al. 2009). For example, by participating in policy forums that operate at regional or higher levels, local actors may communicate information about local environmental conditions, which may help align policy goals with diverse and dynamic local contexts (Olsson et al. 2007, Huitema et al. 2009). Correspondingly, when an actor participates in forums that operate at more local levels than the actor's own level, the actor may share funding priorities or technical information that increase the effectiveness of efforts to address environmental challenges (Carlsson and Berkes 2005, Olsson et al. 2007). Such cross-level linkages, in which actors participate in environmental policy forums above or below their own respective levels, serve as mechanisms for disseminating policy-relevant science, placebased knowledge, and financial resources across multiple levels of environmental governance systems.

Our objective in this paper is to develop and test hypotheses about the conditions under which policy actors initiate cross-level linkages, which Gallemore et al. (2015) suggest is a major gap in literature on the structure and function of multilevel environmental governance systems. We draw upon the recently updated ecology of games framework (EGF; Lubell 2013, Lubell et al. 2014, Berardo et al. 2015), which integrates ideas from polycentric governance with transaction cost analysis (Ostrom et al. 1961, Williamson 1981, North 1990, Ostrom 2010). The EGF argues that policy forums provide opportunities for political contracting, and that participants will develop mutually beneficial agreements if they can overcome the transaction costs of searching for possible solutions, bargaining over the distribution of costs and benefits, and monitoring and enforcing the resulting agreements.

We argue that relative to within-level linkages, cross-level linkages are less common, in large part because they involve higher transaction costs. However, the transaction costs of cross-level

${ }^{1}$ School for Environment and Sustainability, University of Michigan, ${ }^{2}$ Department of Environmental Science and Policy, University of California at Davis, ${ }^{3}$ Department of Geography, Geo-informatics \& Climatic Sciences, Makerere University 
linkages can be mitigated by social capital, i.e., the value of social interaction, which can be measured in terms of collaborative relationships among actors jointly participating in forums, or political capital, i.e., the value of reputation and leadership, which can be assessed in terms of proximity to influential actors. The value of political and social capital may depend on the direction of the cross-level linkage. In particular, actors may acquire financial resources and authority through participation in forums that operate at higher levels than their own levels. Correspondingly, actors may gain the legitimacy needed to influence resource use decisions though participation in forums that operate at lower levels than their own levels.

We investigate the relationship between cross-level linkages and social as well as political capital through empirical analysis of the bipartite policy network (actors participating in forums) that contributes to climate change adaptation governance in the Lake Victoria region, East Africa. Extending over portions of Uganda, Kenya, and Tanzania, the study system features numerous interactions among diverse policy actors and forums. In their efforts to improve adaptive capacity to the effects of climate change that span national boundaries, policy actors confront multiple, interlinked challenges that require collaborative policy responses. For example, in agricultural and pastoral sectors, adaptation hinges upon the ability of local and regional policy actors to collectively plan and implement policy interventions across diverse climate-sensitive local economies (Swallow et al. 2009, Goulden et al. 2013, Vervoort et al. 2014). Similarly, collaboration is required in order to "mainstream" climate change adaptation into water resource management, public health, and other existing policy arenas given inevitable reconfiguration of political authority and resources (Huq et al. 2004). An important characteristic of the study system is that it features actors and forums operating at local, national, regional, and global levels.

\section{The benefits and transaction costs of cross-level linkages in an ecology of policy games}

The EGF (Lubell 2013) provides a set of working hypotheses for actor behavior in complex governance systems. As a theory of polycentric governance (Ostrom et al. 1961, Ostrom 2010), the EGF assumes that actors participate in policy forums in order to gain the benefits from solving collective action problems. However, the political contracting process that occurs within forums involves the transaction costs of searching for different policy solutions, bargaining over the different options, and monitoring and enforcing any resulting agreements (Williamson 1981, Feiock 2007). The EGF assumes that given actors' limited resources, they seek to participate in sets of forums that offer the greatest net benefits (payoffs minus transaction costs). As a result, when deciding whether to participate in a given forum, an actor considers not only the prospective payoffs and transaction costs associated with that particular forum, but also how the forum compares with other forums in terms of potential payoffs/costs. The EGF considers political power as an important part of this process, at the very least for influencing the bargaining process for the distribution of costs and benefits (Knight 1992).

Within- and cross-level linkages offer distinct benefits. For example, by participating in forums at their own levels, actors can focus on issues they consider to be more salient than the scope of issues discussed in forums at higher or lower levels. By contrast, cross-level linkages offer opportunities to access resources, such as information or funding, that may not be available in forums that operate at actors' own respective levels. Although the scope of payoffs associated with within- and cross-level participation depends on the type of benefit evaluated, e.g., ability to focus only on issues most relevant to an actor's policy agenda versus opportunities to secure novel resources, we argue that transaction costs are higher in cross-level linkages compared with within-level linkages.

Relative to cross-level linkages, search costs may be lower in within-level linkages, where actors are more likely to face common problems. By contrast, cross-level linkages require reconciliation of priorities for policy interventions across spatial levels. Carlsson and Sandström (2007) argue that cross-level linkages are inherently heterogeneous, because by definition they span distinct spatial and administrative levels of governance. Heterogeneityof organizational affiliation, policy preferences, or relative power - increases the bargaining costs because any possible solutions require distributing costs and benefits across many different types of actors (Gerber et al. 2013).

Monitoring and enforcement costs may be lower for within-level linkages, which provide a greater opportunity for repeated interaction and the development of trust (Bacharach and Gambetta 2001). Relative to within-level linkages, cross-level linkages feature less repeated interaction, sometimes simply as a consequence of logistical challenges. As Gallemore et al. (2015) observe in their study on Reducing Emissions from Deforestation and Forest Degradation (REDD+) policy in Indonesia, the considerable differences between actors at different levels breeds uncertainty and mistrust. Furthermore, it may be costlier to monitor the behavior of actors involved in cross-level linkages, for example when regional actors have limited opportunities to verify implementation outcomes (Corbera and Schroeder 2011), or when local actors can only sporadically attend international meetings (Fisher and Green 2004). Because cross-level linkages present additional transaction costs (compared with within-level linkages), we hypothesize the following:

H1: Cross-level linkages are less common compared to withinlevel linkages.

Panels A and B of Figure 1 describe this hypothesis from the perspective of bipartite networks of actors participating in forums, and relying on the theory that small structural configurations are the building blocks of larger networks and the relative frequency of different configurations reflects the operation of different social processes (Davis and Leinhardt 1972, Milo et al. 2002, Wang et al. 2013a). The first row of Figure 1 shows upward (Panel A) and downward (Panel B) linkages, which we expect to be rarer than within-level linkages, in which actors participate in forums that operate at their own levels.

\section{Collaborative closure: bonding social capital in cross-level linkages}

In keeping with the transaction cost argument presented in the preceding section, we argue that bonding social capital may affect the propensity of actors to participate in cross-level linkages. Bonding social capital refers to the prevalence of strong relationships that develop within densely connected clusters of 
Fig. 1. Substructures involving cross-level linkages in which policy actors (yellow ovals) participate in climate change adaptation policy forums (blue rectangles) at higher or lower levels. In the diagrams, solid lines indicate actor-forum participation and dashed lines indicate relationships between pairs of actors.

A

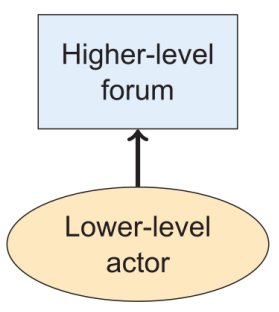

Upward cross-level linkage

C

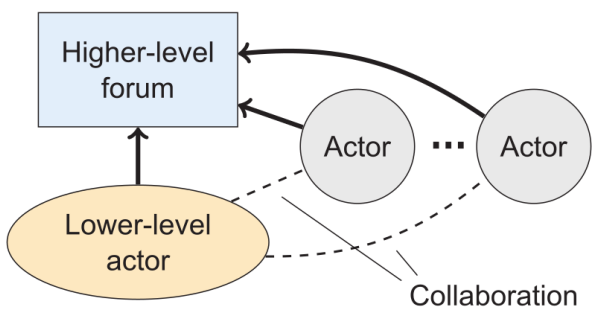

Upward cross-level linkage via collaborative closure

E

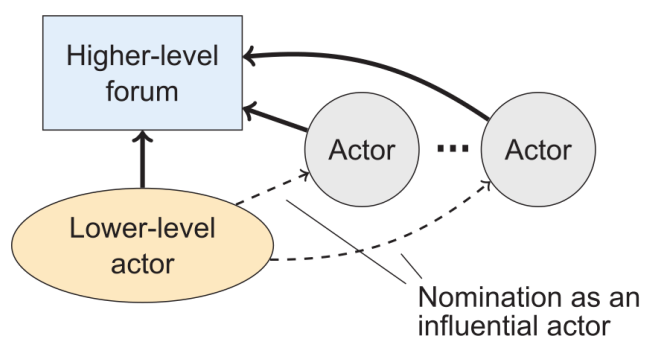

Upward cross-level linkage via influential participant
B

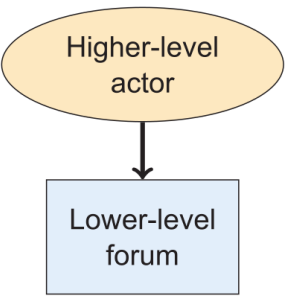

Downward cross-level linkage

$\mathrm{D}$

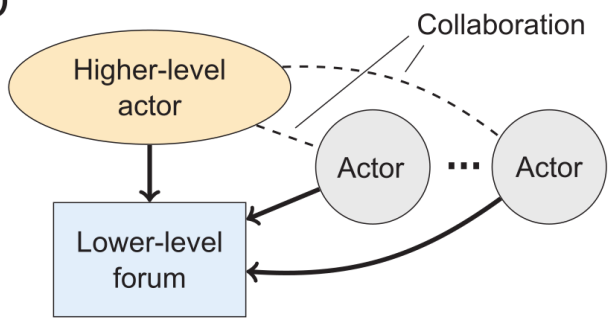

Downward cross-level linkage via collaborative closure

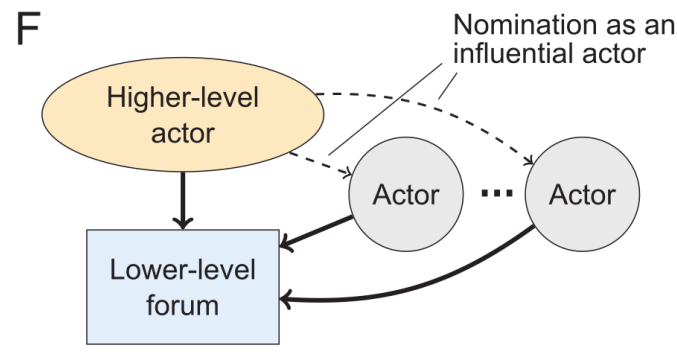

Downward cross-level linkage via influential participant actors (Putnam 2000), and is often associated with trust and norms of reciprocity (Woolcock and Narayan 2000, Pretty and Ward 2001). To operationalize bonding social capital, we draw upon the network science concept of closure, which describes the presence of a relationship between two nodes that are each connected to the same third node. In our case, network closure occurs when actors with a bilateral collaborative relationship participate in the same forum. Although prior research has shown that collaboration is more likely when actors jointly participate in the same policy forums (Fischer and Sciarini 2016), and that this effect is strongest when actors jointly participate in forums operating at lower spatial levels (Hamilton and Lubell 2018), the relationship between collaborative closure and actors' propensities to participate in cross-level linkages has not been evaluated.
We expect closure to be particularly important in mitigating the transaction costs associated with cross-level linkages, which inherently feature higher levels of heterogeneity, e.g., of policy preferences among actors, and are therefore characterized by greater need for mechanisms that reduce monitoring and enforcement costs. In the context of natural resource comanagement policy processes, Carlsson and Sandström (2007) argue that although actors may incur higher transaction costs when initiating cross-level linkages, repeated interaction associated with collaborative relationships may reduce the prospects of conflict over time. Closure provides a means for actors to observe each other's behavior via joint links to a third party (Coleman 1988, Berardo and Scholz 2010), which could be another actor or a policy forum. Consistent with this reasoning, we predict the following: 
H2: The presence of collaborative relationships will be positively associated with cross-level linkages.

Panels C and D of Figure 1 represent upward and downward network closure. In these cases, an actor participates in forum operating at a higher or lower level than the actor's own level and also collaborates with one or more other actors that jointly participate in same forum. For example, if subnational-level actor works with other actors to implement a flood early warning project and also participates in national-level task force on climate change impacts on water resource management, the configuration depicted in Panel $\mathrm{C}$ would reflect a situation in which at least one of actor's project partners also participates in the task force. Ceteris paribus, the presence of collaborators reduces the transaction costs of a cross-level linkage.

\section{Influential actors: political capital in cross-level linkages}

The presence of influential actors in policy forums may provide another conditional effect on the likelihood of cross-level linkages. Following other studies of network governance, we regard proximity to influential actors as an indication of political capital (Sørensen and Torfing 2003, Ingold and Leifeld 2016, Scott and Thomas 2017). As a signal of an actor's authority or capacity, influence can serve as a "search heuristic" (Leifeld and Schneider 2012:733), indicating prospective partners who could provide the most valuable information, or exert their power in support of shared goals. Extending this logic, influential actors could similarly signal the value of policy forums to prospective participants, thereby reducing the cost of searching for appropriate forums to advance a particular policy agenda. We expect this mechanism to play an especially important role in supporting the cross-level linkages, because actors are likely less familiar with the range of forums above or below their own levels of operation and therefore face higher search costs.

In cross-level contexts, influential actors may also mitigate the costs of monitoring and enforcing agreements. The participation of influential actors in policy processes has been linked with the success compliance in natural resource governance systems. In a meta-analysis of the performance of comanagement across 130 fisheries, in which sustainability of fish stocks depends on adherence to quotas and other regulatory mechanisms, Gutiérrez et al. (2011) found that strong leadership was the most important predictor of performance. In multilevel governance systems, because actors are less involved in policy processes that operate above or below their respective levels, it is more difficult for them to ensure that policy will be implemented as designed. In these situations, actors may prioritize forums in which the joint participation of influential actors offers greater assurance of successful policy implementation without the need for costly monitoring and enforcement.

\section{H3: The presence of influential actors will be positively associated with cross-level linkages.}

The third row of Figure 1 represents upward and downward linkages formed through joint participation in a forum with actors considered to be influential (represented by the dashed lines in Fig. 1). Our hypothesis about the relative likelihood of these configurations reflects our expectation that the presence of influential actors reduces the transaction costs of cross-level linkages.

\section{Asymmetries in cross-level linkages}

There are theoretical reasons to argue that the value of social and political capital may be different for downward and upward crosslevel linkages (Carlsson and Sandström 2007). Through upward linkages, actors can gain access to resources such as funding or scientific/technical information (Riedlinger and Berkes 2001, Kern and Bulkeley 2009) but must navigate decision-making processes in which they are typically among the less powerful participants (Adger et al. 2005, Lebel et al. 2005). Morrill (1999) identifies eight reasons why actors operating at more local levels tend to be less powerful than their counterparts operating at higher levels, including dependence upon those actors' willingness to cede authority or distribute resources to lower levels. Other reasons include the greater capacity of interest groups to mobilize and wield political clout at higher levels, as well as the greater diversity of attitudes and preferences at lower levels, which limits the ability of local actors to unify and collectively advance their agenda (Morrill 1999). Actors engaged in upward linkages may encounter higher transaction costs of bargaining with more powerful actors in forum-sponsored decision-making processes. In these circumstances, the joint participation of collaborators provides a form of bonding social capital that can help actors form advocacy coalitions (Sabatier and Jenkins-Smith 1993) for jointly pursuing common policy goals when participating in forums that operate at higher levels than they do.

In contrast, actors may use downward linkages to gain access to place-based knowledge and influential local actors that enhance their capacity to shape local-level decisions and policies (Jasanoff 2004). The capacity to reorient local decisions toward the collective policy goals of a region is one of the key dilemmas of regional governance (Gerber and Gibson 2009). Actors operating at higher levels are less knowledgeable of local realities relevant to policy implementation, which may include awareness of political and economic dynamics as well as which local actors would make the most valuable partners. Similarly, actors operating at higher levels may not be able to readily identify which local policy forums represent the most appropriate forums for addressing a given policy objective, or which forums have the authority (or political support) needed to effectively design and implement policy. The "great expectations" of regional actors may be dashed if they select the "wrong" local partners or forums (Pressman and Wildavsky 1973). In settings characterized by weak institutions or enforcement mechanisms, developing political capital may be the only way for actors operating at higher levels to influence the behavior of more local actors that have significant autonomy. For actors operating at higher levels, the presence of influential actors in a policy forum may signal that the forum has greater capacity to implement their preferred policies (Leifeld and Schneider 2012). Downward linkages to forums with influential actors may involve lower search costs (selecting the most appropriate forums) in the short run, and lower monitoring/enforcement costs in the long run. We predict the following:

H4: Bonding social capital will be more important for upward linkages, while political influence will be more important for downward linkages.

Consistent with this hypothesis, we expect the network configuration depicted in Panel C of Figure 1 to be more likely 
than configuration in Panel D, and the configuration in Panel F to be more likely than the configuration in Panel E.

\section{METHODS}

Study system: climate change adaptation governance in the Lake Victoria region

The climate change adaptation policy process operating in the Lake Victoria region (Fig. 2) serves as a model system for advancing understanding of the dynamics of cross-level and transboundary governance. The Lake Victoria region extends over Northern Tanzania, Southwestern Kenya, and Southern Uganda. A succession of regional governance initiatives dating back to the early 20 th century have resulted in the development of a regional identity centered on shared economic and geopolitical interests. This identity is perhaps most strongly reflected in the aspirations and activities of the East African Community, an intergovernmental organization that promotes regional integration of partner states through bodies such as the East African Legislative Assembly, and semiautonomous specialized organizations such as the Lake Victoria Basin Commission and the Lake Victoria Fisheries Organization.

Fig. 2. Map of the study region. Green circles indicate fieldwork locations.

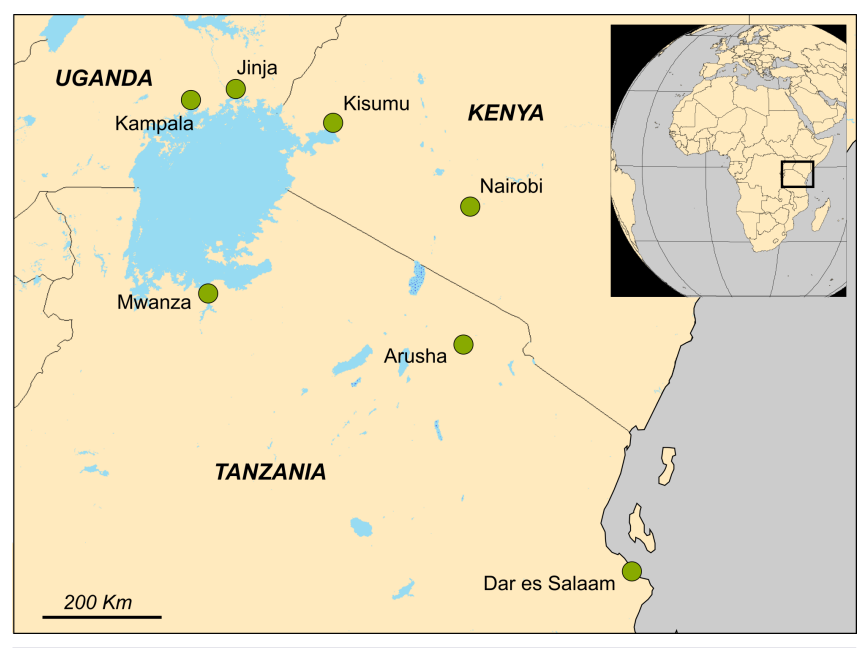

Climate change adaptation is an emerging policy issue in the region, and represents an archetypal multilevel governance problem where the adaptive capacity of local communities is influenced by governance institutions and actors at the local, national, regional, and global levels (Termeer et al. 2010). In the Lake Victoria region, adaptation challenges stem in part from extensive participation in climate-sensitive economic livelihoods such as rain-fed agriculture, small-scale fishing, and pastoralism (AfDB/IFAD 2009, Thornton et al. 2009, Hecky et al. 2010, Tyus 2011). The agricultural sector is an illustrative example of the multilevel nature of these problems. Household-level adaptation may focus on or include crop diversification or the replacement of susceptible crop varieties with more heat tolerant cultivars (Cooper et al. 2008). At higher administrative levels, adaptation interventions may include agricultural extension that combines research with outreach to local producer networks to facilitate adoption of agricultural technologies deemed more appropriate given changing weather patterns (Asfaw et al. 2012). Nationallevel initiatives include a range of planning and agenda-setting policy tools, such as the Uganda National Climate Change Policy and the Tanzania National Adaptation Programme of Action. These national-level policies seek to guide adaptation actions at lower administrative levels, for example through appropriation of funding to high-priority policy sectors, and also serve as mechanisms for engaging policy processes at the regional to global level.

The governance system is also polycentric (Ostrom et al. 1961, Ostrom 2010) and features multiple decision-making forums in which actors collaborate to design and implement climate change adaptation policy. These range from task forces and advisory committees that meet on an ad hoc basis to highly institutionalized forums such as the United Nations Framework Convention on Climate Change Conferences of the Parties. Governance outcomes reflect patterns of collaboration among actors as well as their participation in multiple policy forums, which may operate at different spatial levels or address different phases of the policy process, i.e., design versus implementation.

\section{Data collection}

We gathered our data through a survey of climate change adaptation policy actors (organizations) operating within the Lake Victoria region. Respondents were identified through a twostep process. First, we developed a list of organizations through Internet search and document review, which was reviewed and slightly extended by a research steering committee composed of regional experts from Uganda, Tanzania, and Kenya. Second, for each organization, we identified at least one individual knowledgeable of the organization's involvement in climate change adaptation activities. These individuals were identified through a combination of Internet search, document review, and nomination by members of the research steering committee. Several were nominated by other survey respondents. Respondents were either their organization's focal person for climate change-related activities or occupied programmatic leadership or administrative positions and were therefore knowledgeable of their organization's climate change adaptation activities, including participation in the policy process.

We administered the survey February-July 2014, primarily in face-to-face meetings with respondents at their places of work. Fieldwork locations included Kampala, Entebbe, and Jinja in Uganda; Nairobi and Kisumu in Kenya; and Dar es Salaam, Arusha, and Mwanza in Tanzania. These cities are starred in Figure 2. The in-person format provided us the opportunity to confirm that respondents understood questions as we had intended. Visiting respondents in person likely resulted in a higher response rate. Additionally, through dialog with respondents while completing the survey, we gained qualitative insight that facilitated interpretation of results of analysis. We administered in-person surveys to representatives of 125 organizations. Several prospective respondents indicated their interest in participating but were not available to meet in person. These individuals received a web-based version of the survey. Representatives of an additional 19 organizations were surveyed in this way. In total, we received responses from representatives of 144 organizations, for an American Association for Public Opinion Research (AAPOR) estimated response rate of $59 \%$. 
Table 1. Cross-tabulation and examples of actors and forums operating at different levels within the Lake Victoria region climate change adaptation governance system.

\begin{tabular}{lll}
\hline \hline Level & Actors (number and examples) & Forums (number and examples) \\
\hline Regional and higher & $\mathrm{N}=33$ & $\mathrm{~N}=38$ \\
& Lake Victoria Basin Commission & East African Climate Change Working Group \\
& USAID East Africa & Greater Horn of Africa Climate Outlook Forum \\
& Lake Victoria Region Local Authorities Cooperation & Mitigation of Climate Change in Agriculture \\
& & Programme \\
National and lower & $\mathrm{N}=76$ & $\mathrm{~N}=46$ \\
& Ministry of Environment, Water and Natural & Tanzania Development Partners Group on Environment \\
& Resources (Kenya) & \\
& Uganda Coalition for Sustainable Development & Kenya Food Security Steering Group \\
& Tanzania Forest Conservation Group & Uganda National Development Plan \\
\hline
\end{tabular}

\section{Analytical approach: exponential random graph modeling}

Upward and downward cross-level linkages constitute our dependent variables. To evaluate the likelihood of cross-level linkages relative to within-level linkages $(\mathrm{H} 1)$ and the conditional effects of collaborative closure and influential actors on crosslevel linkages ( $\mathrm{H} 2$ and $\mathrm{H} 3$, respectively), we estimated exponential random graph models (ERGMs) of our actor-forum bipartite network. ERGMs provide a means of statistical inference that accounts for interdependence among observations (Robins et al. 2007, Cranmer and Desmarais 2011), which is an inherent characteristic of network data. An ERGM treats the empirical network as one realization of many plausible networks in which the same relational processes operate and generate similar structural patterns. Markov chain Monte Carlo simulation techniques are used to generate a series of networks based on a set of initial parameter values. These values are refined through iterative comparison of network statistics between the empirical and simulated networks, until they finally converge on maximum likelihood parameter estimates. We estimated a baseline model, which specifically assessed the relative prevalence of cross-level ties, as well as a full model, which tested the conditional effects of collaborative closure and influential participants on cross-level linkages. All analyses were conducted using the "statnet" suite of packages (Handcock et al. 2008) in R version 3.3 (R Core Team 2016).

\section{Model parameters}

Our first hypothesis focuses on the relative frequency of crosslevel linkages, in which policy actors (organizations) at one administrative level participate in policy forums at a different administrative level. The survey prompted respondents to identify up to 12 forums that their organization leads or participates in. Specifically, the survey defined forums using the following language: "Climate change adaptation can be addressed in different kinds of projects, programs, forums or planning processes where multiple organizations collaborate to make decisions about the design and implementation of climate change adaptation activities." We used these data to construct a bipartite network of policy actors (organizations) linked to policy forums. We coded actors and forums based on the levels at which they operate. Specifically, one class included actors and forums operating at the national or subnational level and another class included actors and forums operating at the level of the Lake Victoria region or higher (Table 1). Although this approach sacrificed some degree of detail that could have been captured through a finer-grained treatment of spatial levels, e.g., by distinguishing between actors operating at the subnational versus national level, or between forums operating within the Lake Victoria region versus East Africa, it allowed us to be more confident about the results of the classification. For example, many actors work primarily in communities, but these communities are distributed throughout a nation. After designating the levels at which actors and forums operate, we turned to the actor-forum network, and distinguished between "upward linkages" (XL-UP, Panel A of Fig. 1) and "downward linkages" (XL-DOWN, Panel B) based on whether actors participate in forums above or below their respective levels.

Our second hypothesis focuses on the conditional effect of collaborative closure on cross-level linkages. For each actorforum linkage, we measured collaborative closure in terms of the number of the actor's collaborators that jointly participate in the forum. To measure collaborative ties between actors, we prompted respondents to identify the "organizations your organization has collaborated with in the context of climate change adaptation in the past year." Panels C and D of Figure 1 depict upward (XLUP VIA COLLABORATIVE CLOSURE) and downward (XLDOWN VIA COLLABORATIVE CLOSURE) cross-level linkages that exhibit collaborative closure. For each cross-level actor-forum linkage, the value of each parameter was calculated based on the number of collaborators jointly participating in the forum. For example, if an actor jointly participated with two collaborators in a forum operating at a higher level, the XL-UP VIA COLLABORATIVE CLOSURE parameter would take the value of 2 .

Our third hypothesis focuses on the conditional effect of influential actors. In a similar fashion as how we measured collaborative relationships between actors, we prompted respondents to identify influential actors using the following question: "Out of all the organizations involved with climate change adaptation issues in the Lake Victoria region, please list up to 6 that you believe are most influential (excluding your own organization). Please also consider organizations that your organization does not collaborate with." The dashed ties connecting actors in panels $\mathrm{E}$ and $\mathrm{F}$ of Figure 1 reflect this relational treatment of influence. The parameters XL-UP VIA INFLUENTIAL PARTICIPANTS and XL-DOWN VIA INFLUENTIAL PARTICIPANTS correspond to the upward 
Fig. 3. Visualization of the Lake Victoria region climate change adaptation policy network. Nodes correspond to actors (circles) and forums (squares), and are colored according to whether they operate at the national or lower level (red) or at the regional or higher level (blue). Linkages represent participation by actors in policy forums. The size of each node is proportionate to the number of linkages to other nodes.

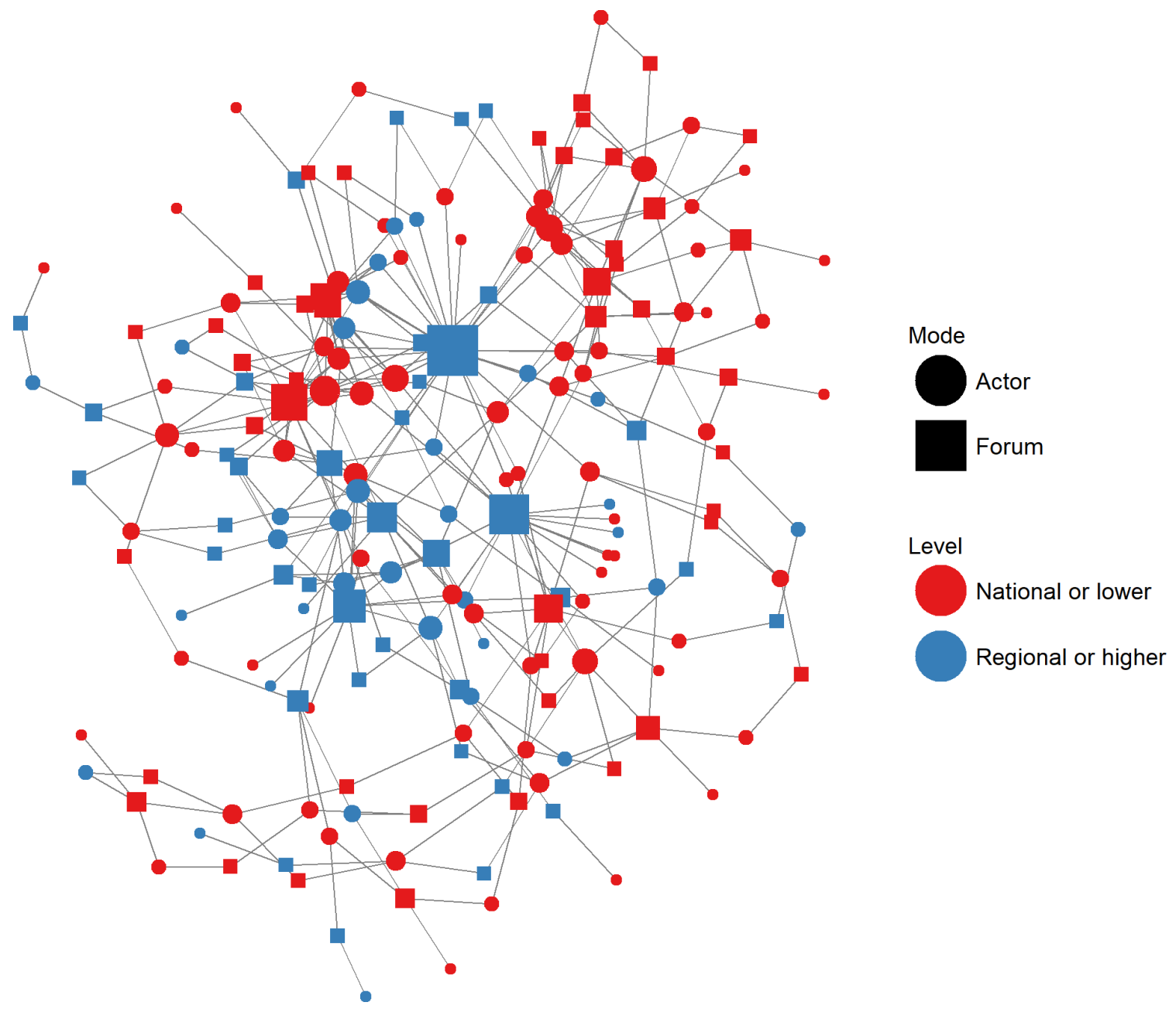

and downward variants of these structures. The values of these parameters were calculated in a similar fashion as the collaborative closure parameters, i.e., for each cross-level actorforum linkage, parameter values equal the number of joint participants nominated as influential by the actor.

The separate measurement of upward and downward linkages enabled us to evaluate our fourth hypothesis. Specifically, we assessed the relative frequency of upward or downward linkages associated with social or political capital based on differences in the magnitude of ERGM parameters associated with both forms of capital and cross-level linkages.

We also included several parameters that serve to either control for actor attributes or help us more directly evaluate the crosslevel parameters used to test our hypotheses. For example, the parameters COLLABORATIVE CLOSURE and INFLUENTIAL PARTICIPANTS measure the number of joint forum participants identified as collaborators or regarded as influential, respectively, by the actor in each actor-forum linkage, regardless of whether those linkages are cross-level. Other control parameters measure the prevalence of more complex structures in the network. For example, we include the parameters GW (ACTOR) DEGREE and GW (FORUM) DEGREE to control for the distribution of actor linkages, i.e., the number of forums each actor participates in, and forum linkages, i.e., the number of actors that participate in each forum. The full range of control parameters are described in detail in Appendix 1, which also discusses their effects in the models. Appendix 2 describes the tests conducted to examine and confirm the goodness of model fit.

\section{RESULTS}

Figure 3 is a visualization of the bipartite climate change adaptation actor-forum policy network operating in the Lake Victoria region. Of the 144 organizations (actors) included in the survey, 14 reported no participation in forums and were excluded from the analysis. Forums in which only one actor participated were also excluded from the analysis, as were actors that only 
Table 2. Results of exponential random graph models.

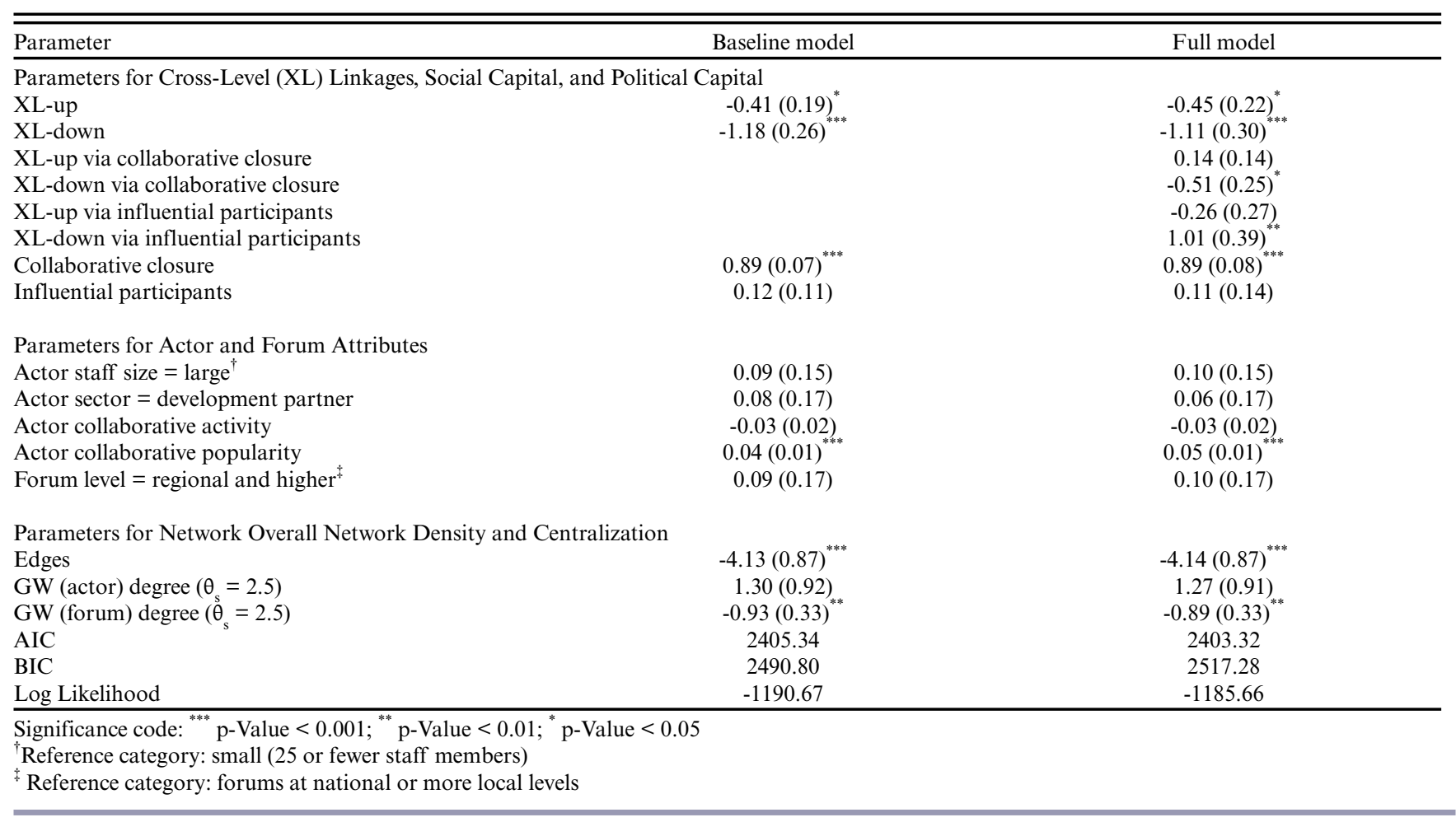

participated in these forums. This methodological approach allowed us to focus on dynamics characterizing the "core" of the climate change adaptation governance system operating in the Lake Victoria region. Because environmental governance networks typically lack a well-defined "boundary" that distinguishes between actors or forums within and external to the governance system, a focus on the core network additionally serves to mitigate the effects of undersampling more peripheral actors/forums. The resulting network comprises 109 actors and 84 forums. The network features a large connected component that occupies much of the visualization and highlights the central position of several forums operating at the regional level or higher. Such visualizations provide an intuitive representation of the general structure of the policy network. However, to test our hypotheses about the processes that give rise to this structure, we turn to inferential analysis.

We present ERGM results in Table 2. Parameter estimates indicate the conditional log odds of observing each parameter and may be interpreted in a similar way as logistic regression coefficients. The negative estimates for the XL-UP and XL-DOWN parameters provide support for our first hypothesis: that crosslevel linkages are less common compared to within-level linkages.

Results do not support our second hypothesis: that collaborative closure would be positively associated with cross-level linkages. The negative coefficient for XL-DOWN VIA COLLABORATIVE CLOSURE indicates that the likelihood of a downward linkage to a particular policy forum decreases with the number of collaborators that jointly participate in that forum. The estimate for XL-UP VIA COLLABORATIVE CLOSURE is positive, but not significant.
We found mixed support for our third hypothesis: that joint participation of influential actors would be positively associated with cross-level linkages. The XL-UP VIA INFLUENTIAL PARTICIPANTS coefficient was negative, but not significant. However, the positive and significant coefficient for XL-DOWN VIA INFLUENTIAL PARTICIPANTS indicates that the likelihood downward linkage to a particular policy forum increases with the number of influential actors that jointly participate in that forum.

Our fourth hypothesis focused on the possibility of asymmetries in the conditional effects of bonding social capital and political capital on cross-level linkages. Specifically, we expected that collaborative closure would be more important for upward linkages, while the presence of influential actors would be more important for downward linkages. Indeed, the presence of influential joint participants significantly increased the likelihood of downward linkages, compared to upward linkages. However, this hypothesis was only partially supported. Although collaborative closure decreased the likelihood of downward linkages, this effect was not significant for upward linkages.

Although estimates for the control parameters relate to the likelihood of actor-forum linkages, rather than the likelihood of cross-level linkages, they nevertheless shed light on other key factors that shape the structure of the climate change adaptation policy network operating in the Lake Victoria region. For example, the COLLABORATIVE CLOSURE parameter is positive and significant in the baseline model, indicating that actors are more likely to participate in forums in which their collaborators jointly participate. Because the full model includes XL-UP VIA COLLABORATIVE CLOSURE and XL-DOWN 
VIA COLLABORATIVE CLOSURE, the positive and significant effect of the COLLABORATIVE CLOSURE parameter indicates that actors are specifically more likely to participate in forums and operate at their own levels, in which their collaborators also participate. The negative GW (FORUM) DEGREE parameter estimate indicates a tendency for centralization around forums. In other words, actors tend to participate in forums that have many, rather than few, other participants. Appendix 1 describes and interprets the effects of the remaining parameters.

\section{DISCUSSION AND CONCLUSION}

Our investigation of climate change adaptation policy processes in the Lake Victoria region highlights a core challenge of multilevel governance: actors tend to favor within-level rather than cross-level policy linkages, which may limit the capacity of the governance system to effectively respond to vertical interplay among its ecological or political components. Although numerous factors undoubtedly contribute to the costs and benefits of within- and cross-level linkages, e.g., relevance of the focal issues of the forum or opportunities for accessing novel information, our findings are consistent with a growing body of work that argues that compared to within-level linkages, crosslevel linkages are less common in part because they impose higher transaction costs (Adger et al. 2005, Termeer et al. 2010, 2011, Gallemore et al. 2015). However, despite important theoretical work on the role of cross-level linkages in environmental governance settings (Carlsson and Sandström 2007), there is limited understanding of the conditions under which policy actors interact across geographic and administrative levels, due to a lack of empirical studies that test hypotheses about how actors themselves may benefit and incur costs as a result of participating in these linkages (but see Gallemore et al. 2015). We addressed this deficiency by accounting for the local network structure in which actors and policy forums are embedded.

Our analysis also highlights the inherently different sets of opportunities and constraints when actors participate in policy forums above or below their own levels. In particular, although the joint participation of collaborators may provide the solidarity needed to advance a policy agenda or extract commitments, such support may not be necessary for actors engaged in downward linkages. This finding is consistent with arguments that actors operating at higher levels tend to have more capacity, resources, and power compared to their more local counterparts (Lebel et al. 2005). Hence, for these actors, there may be less necessity to develop collaborative relationships in order to advance policy preferences through downward linkages. In fact, when actors weigh the prospective benefits of downward linkages, they may be reluctant to participate in forums alongside partners with whom they may need to compete to claim credit for development outcomes (Annen and Moers 2012). Viewed another way, this finding helps contextualize prior research on how actors operating at higher levels compete to influence policy at lower levels, particularly in international development settings (Gibson et al. 2005, Horning 2008). To the extent that these actors include international aid organizations, i.e., development partners or international NGOs, this dynamic may indicate effective coordination, in which actors mitigate the potential for aid fragmentation by avoiding forums operating at more local levels in which collaborators already participate (Steinwand 2015).
We found that the effect of influential actors was also conditional on whether linkages were upward or downward in nature. Actors were more likely to participate in policy forums operating at levels lower than their own if influential actors also participated in those forums. This finding is consistent with our arguments that influential actors may (1) signal the relative importance of forums that operate at lower levels than an actor's own level, which can reduce the search costs actors face when trying to identify the effective forum in which to advance a particular policy goal, and (2) reduce (or obviate) the need for costly monitoring and enforcement of policies implemented at lower administrative levels. Although the "signaling" mechanism would apply chiefly to actors that are unfamiliar with local-level political dynamics, we believe that the appeal of authority is more generalizable, given the limited capacity of actors that operate at higher levels to ensure that policies are implemented as designed.

An important limitation of the present study is our inability to distinguish between different potential causal mechanisms that shape the patterns of forum participation we observe in our crosssectional data. For example, just as collaborative closure may affect how actors make decisions about forum participation, joint forum participation may likewise influence collaboration (Hamilton and Lubell 2018). An overarching hypothesis is that actor strategies that influence the selection of forums as well as collaborators are dynamically coupled, and longitudinal studies could greatly assist in determining the extent to which conditions such as collaborative closure and influential participants facilitate/impede the formation of different types of cross-level linkages. Given the importance of accounting for multiple forms of policy linkages, e.g., participation, collaboration, and influence, and the multiple types of entities in governance networks, e.g., actors and forums, methodological advances in the analysis of multiplex and multilevel networks (Snijders et al. 2013, Wang et al. 2013b) could generate additional valuable insight. In complex institutional settings such as the Lake Victoria climate change adaptation governance system, greater understanding of how relational patterns, e.g., cross-level linkages, reflect the strategies and behaviors of individual policy actors will help policy makers and other stakeholders more effectively navigate policy processes while contributing to societal goals.

It is important to note that certain social and political dynamics that characterize cross-level linkages in East African policy processes may operate differently in other governance systems, particularly those in industrialized regions. For example, while the concentration of capacity, resources, and power at higher administrative levels may be generalizable to most governance systems, this dynamic is often much stronger in policy processes that span multiple countries in developing regions. In their interactions with global actors, national actors in developing regions typically have considerably less resources and power compared to their counterparts in developed regions (Adger et al. 2001, 2005). Likewise, nongovernmental organizations that operate in developed regions are generally much less powerful than similar organizations in developed regions (Ribot and Peluso 2003, Sovacool and Linnér 2016). As a result, the conditional effects of collaborative closure and influential joint participants may be weaker in governance systems in developed regions. 
Although this study provided a theoretical framework and empirical analysis of the formation of different types of linkages, we do not address the question of what distribution of withinlevel and cross-level linkages is most effective for improving governance processes, e.g., facilitating policy learning. For example, given the necessity of balancing benefits and transaction costs, it is unlikely that effective governance requires establishing all possible cross-level linkages. Furthermore, the most beneficial balance of cross-level linkages is likely to change over time as governance systems encounter new policy challenges. Designing future research to answer these types of questions is crucial because of the complex causal relationships between multilevel institutional arrangements, social processes such as learning, and policy outputs and outcomes. Discovering definitive answers to these bigger questions is a major challenge in theory and research design, because the optimal mix of networks is likely to be diverse over space and dynamic over time, reflecting both local socialecological contexts and macro-level political institutions.

Responses to this article can be read online at: http://www.ecologyandsociety.org/issues/responses. php/10179

\section{Acknowledgments:}

We thank Shuaib Lwasa, Paul Onyango, and Charles Mundia for valuable recommendations and logistical assistance preceding and during fieldwork. Earlier versions of this paper were presented at the 2016 American Association of Geographers Annual Meeting in San Francisco, CA, the 2016 Midwest Political Science Association Annual Conference in Chicago, IL, and the 2017 Environmental Politics and Governance Conference in Bloomington, IN. We thank conference participants and discussants for valuable feedback. Research was partially supported by NSF Division of Graduate Education (DGE) \#0801430, the Responding to Rapid Environmental Change ( REACH) IGERT awarded to UC Davis, and a Jastro-Shields grant from UC Davis. We thank two anonymous reviewers for their helpful suggestions.

\section{LITERATURE CITED}

Adger, W. N., T. A. Benjaminsen, K. Brown, and H. Svarstad. 2001. Advancing a political ecology of global environmental discourses. Development and Change 32(4):681-715. http://dx.doi. org/10.1111/1467-7660.00222

Adger, W. N., K. Brown, and E. L. Tompkins. 2005. The political economy of cross-scale networks in resource co-management. Ecology and Society 10(2):9. http://dx.doi.org/10.5751/ES-01465-100209

African Development Bank and International Fund for Agricultural Development (AfDB/IFAD). 2009. AFDB/IFAD Joint Evaluation of their agricultural operations and policies in Africa. African Development Bank, Rome, Italy.

Annen, K., and L. Moers. 2012. Donor competition for aid impact, and aid fragmentation. IMF Working Paper 12/204. International Monetary Fund, Washington, D.C., USA.
Ansell, C., and A. Gash. 2008. Collaborative governance in theory and practice. Journal of Public Administration Research and Theory 18(4):543-571. http://dx.doi.org/10.1093/jopart/mum032

Asfaw, S., B. Shiferaw, F. Simtowe, and L. Lipper. 2012. Impact of modern agricultural technologies on smallholder welfare: evidence from Tanzania and Ethiopia. Food Policy 37(3):283-295. http://dx.doi.org/10.1016/j.foodpol.2012.02.013

Bacharach, M., and D. Gambetta. 2001. Trust in signs. Pages 148-184 in K. S. Cook, editor. Trust in society. SAGE, New York, New York, USA.

Berardo, R., T. Olivier, and A. Lavers. 2015. Focusing events and changes in ecologies of policy games: evidence from the Paraná River Delta. Review of Policy Research 32(4):443-464. http://dx. doi.org/10.1111/ropr.12128

Berardo, R., and J. T. Scholz. 2010. Self-organizing policy networks: risk, partner selection, and cooperation in estuaries American Journal of Political Science 54(3):632-649. http://dx.doi. org/10.1111/j.1540-5907.2010.00451.x

Berkes, F. 2002. Cross-scale institutional linkages for commons management: perspectives from the bottom up. Pages 293-321 in E. Ostrom, T. Dietz, N. Dolšak, P. C. Stern, S. Stonich, and E. U. Weber, editors. The drama of the commons. National Academies Press, Washington, D.C., USA.

Brondizio, E. S., E. Ostrom, and O. R. Young. 2009. Connectivity and the governance of multilevel social-ecological systems: the role of social capital. Annual Review of Environment and Resources 34(1):253-278. http://dx.doi.org/10.1146/annurev.environ.020708.100707

Carlsson, L., and F. Berkes. 2005. Co-management: concepts and methodological implications. Journal of Environmental Management 75(1):65-76. http://dx.doi.org/10.1016/j.jenvman.2004.11.008

Carlsson, L. G., and A. C. Sandström. 2007. Network governance of the commons. International Journal of the Commons 2 (1):33-54. http://dx.doi.org/10.18352/ijc.20

Cash, D. W., W. Adger, F. Berkes, P. Garden, L. Lebel, P. Olsson, L. Pritchard, and O. Young. 2006. Scale and cross-scale dynamics: governance and information in a multilevel world. Ecology and Society 11(2):8. http://dx.doi.org/10.5751/ES-01759-110208

Coleman, J. S. 1988. Social capital in the creation of human capital. American Journal of Sociology 94:S95-S120. http://dx. doi.org/10.1086/228943

Cooper, P. J. M., J. Dimes, K. P. C. Rao, B. Shapiro, B. Shiferaw, and S. Twomlow. 2008. Coping better with current climatic variability in the rain-fed farming systems of sub-Saharan Africa: an essential first step in adapting to future climate change? Agriculture, Ecosystems \& Environment 126(1-2):24-35. http://dx. doi.org/10.1016/j.agee.2008.01.007

Corbera, E., and H. Schroeder. 2011. Governing and implementing REDD+. Environmental Science \& Policy 14 (2):89-99. http://dx.doi.org/10.1016/j.envsci.2010.11.002

Cranmer, S. J., and B. A. Desmarais. 2011. Inferential network analysis with exponential random graph models. Political Analysis 19(1):66-86. http://dx.doi.org/10.1093/pan/mpq037 
Davis, J. A., and S. Leinhardt. 1972. The structure of positive interpersonal relations in small groups. Pages 218-251 in J. Berger, editor. Sociological theories in progress. Houghton Mifflin, Boston, Massachusetts, USA.

Feiock, R. C. 2007. Rational choice and regional governance. Journal of Urban Affairs 29(1):47-63. http://dx.doi.org/10.1111/ j.1467-9906.2007.00322.x

Fischer, M., and P. Leifeld. 2015. Policy forums: Why do they exist and what are they used for? Policy Sciences 48(3):363-382. http://dx.doi.org/10.1007/s11077-015-9224-y

Fischer, M., and P. Sciarini. 2016. Drivers of collaboration in political decision-making: a cross-sector perspective. Journal of Politics 78(1):63-74. http://dx.doi.org/10.1086/683061

Fisher, D. R., and J. F. Green. 2004. Understanding disenfranchisement: civil society and developing countries' influence and participation in global governance for sustainable development. Global Environmental Politics 4(3):65-84. http://dx. doi.org/10.1162/1526380041748047

Gallemore, C., M. Di Gregorio, M. Moeliono, M. Brockhaus, and R. D. Prasti H. 2015. Transaction costs, power, and multilevel forest governance in Indonesia. Ecological Economics 114:168-179. http://dx.doi.org/10.1016/i.ecolecon.2015.03.024

Gerber, E. R., and C. C. Gibson. 2009. Balancing regionalism and localism: how institutions and incentives shape American transportation policy. American Journal of Political Science 53 (3):633-648. http://dx.doi.org/10.1111/j.1540-5907.2009.00391.x

Gerber, E. R., A. D. Henry, and M. Lubell. 2013. Political homophily and collaboration in regional planning networks. American Journal of Political Science 57(3):598-610. http://dx.doi. org/10.1111/ajps.12011

Gibson, C. C., K. Andersson, E. Ostrom, and S. Shivakumar. 2005. The Samaritan's dilemma: the political economy of development aid. Oxford University Press, Oxford, UK. http://dx. doi.org/10.1093/0199278857.001.0001

Goulden, M. C., W. N. Adger, E. H. Allison, and D. Conway. 2013. Limits to resilience from livelihood diversification and social capital in lake social-ecological systems. Annals of the Association of American Geographers 103(4):906-924. http://dx. doi.org/10.1080/00045608.2013.765771

Gutiérrez, N. L., R. Hilborn, and O. Defeo. 2011. Leadership, social capital and incentives promote successful fisheries. Nature 470(7334):386-389. http://dx.doi.org/10.1038/nature09689

Hamilton, M., and M. Lubell. 2018. Collaborative governance of climate change adaptation across spatial and institutional scales. Policy Studies Journal 46:222-247. http://dx.doi.org/10.1111/ psj.12224

Handcock, M. S., D. R. Hunter, C. T. Butts, S. M. Goodreau, and M. Morris. 2008. statnet: Software tools for the representation, visualization, analysis and simulation of network data. Journal of Statistical Software 24(1):1548-7660. http://dx.doi.org/10.18637/ jss.v024.i01

Hecky, R. E., R. Mugidde, P. S. Ramlal, M. R. Talbot, and G. W. Kling. 2010. Multiple stressors cause rapid ecosystem change in
Lake Victoria. Freshwater Biology 55:19-42. http://dx.doi. org/10.1111/j.1365-2427.2009.02374.X

Horning, N. R. 2008. Strong support for weak performance: donor competition in Madagascar. African Affairs 107 (428):405-431. http://dx.doi.org/10.1093/afraf/adn036

Huitema, D., E. Mostert, W. Egas, S. Moellenkamp, C. PahlWostl, and R. Yalcin. 2009. Adaptive water governance: assessing the institutional prescriptions of adaptive (co-)management from a governance perspective and defining a research agenda. Ecology and Society 14(1):26. http://dx.doi.org/10.5751/ES-02827-140126

Huq, S., H. Reid, M. Konate, A. Rahman, Y. Sokona, and F. Crick. 2004. Mainstreaming adaptation to climate change in least developed countries (LDCs). Climate Policy 4(1):25-43. http://dx. doi.org/10.1080/14693062.2004.9685508

Ingold, K., and P. Leifeld. 2016. Structural and institutional determinants of influence reputation: a comparison of collaborative and adversarial policy networks in decision making and implementation. Journal of Public Administration Research and Theory 26(1):1-18. http://dx.doi.org/10.1093/jopart/muu043

Jasanoff, S. 2004. Earthly politics: local and global in environmental governance. MIT Press, Cambridge, Massachusetts, USA.

Kern, K., and H. Bulkeley. 2009. Cities, Europeanization and multi-level governance: governing climate change through transnational municipal networks. Journal of Common Market Studies 47(2):309-332. http://dx.doi.org/10.1111/j.1468-5965.2009.00806. $\underline{\mathrm{X}}$

Knight, J. 1992. Institutions and social conflict. Cambridge University Press, Cambridge, UK. http://dx.doi.org/10.1017/ CBO9780511528170

Lebel, L., P. Garden, and M. Imamura. 2005. The politics of scale, position, and place in the governance of water resources in the Mekong region. Ecology and Society 10(2):18. http://dx.doi. org/10.5751/ES-01543-100218

Leifeld, P., and V. Schneider. 2012. Information exchange in policy networks. American Journal of Political Science 56(3):731-744. http://dx.doi.org/10.1111/j.1540-5907.2011.00580.x

Lubell, M. 2013. Governing institutional complexity: the ecology of games framework. Policy Studies Journal 41(3):537-559. http:// dx.doi.org/10.1111/psj.12028

Lubell, M., G. Robins, and P. Wang. 2014. Network structure and institutional complexity in an ecology of water management games. Ecology and Society 19(4):23. http://dx.doi.org/10.5751/ ES-06880-190423

Milo, R., S. Shen-Orr, S. Itzkovitz, N. Kashtan, D. Chklovskii, and U. Alon. 2002. Network motifs: simple building blocks of complex networks. Science 298(5594):824-827. http://dx.doi. org/10.1126/science.298.5594.824

Morrill, R. 1999. Inequalities of power, costs and benefits across geographic scales: the future uses of the Hanford reservation. Political Geography 18(1):1-23. http://dx.doi.org/10.1016/ $\underline{\text { S0962-6298(98)00062-6 }}$

North, D. C. 1990. A transaction cost theory of politics. Journal of Theoretical Politics 2(4):355-367. http://dx.doi. org/10.1177/0951692890002004001 
Olsson, P., C. Folke, V. Galaz, T. Hahn, and L. Schulz. 2007. Enhancing the fit through adaptive co-management: creating and maintaining bridging functions for matching scales in the Kristianstads Vattenrike Biosphere Reserve Sweden. Ecology and Society 12(1):28. http://dx.doi.org/10.5751/ES-01976-120128

Ostrom, E. 2010. Beyond markets and states: polycentric governance of complex economic systems. American Economic Review 100(3):641-672. http://dx.doi.org/10.1257/aer.100.3.641

Ostrom, V., C. M. Tiebout, and R. Warren. 1961. The organization of government in metropolitan areas: a theoretical inquiry. American Political Science Review 55(4):831-842. http:// dx.doi.org/10.1017/S0003055400125973

Pressman, J. L., and A. Wildavsky. 1973. Implementation. University of California Press, Berkeley, California, USA.

Pretty, J., and H. Ward. 2001. Social capital and the environment. World Development 29(2):209-227. http://dx.doi.org/10.1016/ $\underline{\mathrm{S} 0305-750 \mathrm{X}(00) 00098-\mathrm{X}}$

Putnam, R. D. 2000. Bowling alone: the collapse and revival of American community. Simon and Schuster, New York, New York, USA.

R Core Team. 2016. R: A language and environment for statistical computing. R Foundation for Statistical Computing, Vienna, Austria.

Ribot, J. C., and N. L. Peluso. 2003. A theory of access. Rural Sociology 68(2):153-181. http://dx.doi.org/10.1111/j.1549-0831.2003. tb00133.x

Riedlinger, D., and F. Berkes. 2001. Contributions of traditional knowledge to understanding climate change in the Canadian Arctic. Polar Record 37(203):315-328. http://dx.doi.org/10.1017/ $\underline{\mathrm{S} 0032247400017058}$

Robins, G., P. Pattison, Y. Kalish, and D. Lusher. 2007. An introduction to exponential random graph $\left(p^{*}\right)$ models for social networks. Social Networks 29(2):173-191. http://dx.doi. org/10.1016/j.socnet.2006.08.002

Sabatier, P. A., and H. C. Jenkins-Smith. 1993. Policy change and learning: an advocacy coalition approach. Westview, Boulder, Colorado, USA.

Scott, T. A., and C. W. Thomas. 2017. Winners and losers in the ecology of games: network position, connectivity, and the benefits of collaborative governance regimes. Journal of Public Administration Research and Theory 27(4):647-660. http://dx.doi. org/10.1093/jopart/mux009

Snijders, T. A. B., A. Lomi, and V. J. Torló. 2013. A model for the multiplex dynamics of two-mode and one-mode networks, with an application to employment preference, friendship, and advice. Social Networks 35(2):265-276. http://dx.doi.org/10.1016/j. $\underline{\text { socnet.2012.05.005 }}$

Sørensen, E., and J. Torfing. 2003. Network politics, political capital, and democracy. International Journal of Public Administration 26(6):609-634. http://dx.doi.org/10.1081/PAD-120019238

Sovacool, B. K., and B.-O. Linnér. 2016. The political economy of climate change adaptation. Palgrave Macmillan, New York, New York, USA. http://dx.doi.org/10.1057/9781137496737
Steinwand, M. C. 2015. Compete or coordinate? Aid fragmentation and lead donorship. International Organization 69 (2):443-472. http://dx.doi.org/10.1017/S0020818314000381

Swallow, B. M., J. K. Sang, M. Nyabenge, D. K. Bundotich, A. K. Duraiappah, and T. B. Yatich. 2009. Tradeoffs, synergies and traps among ecosystem services in the Lake Victoria basin of East Africa. Environmental Science \& Policy 12(4):504-519. http://dx. doi.org/10.1016/i.envsci.2008.11.003

Termeer, C., A. Dewulf, and M. van Lieshouth. 2010. Disentangling scale approaches in governance research: comparing monocentric, multilevel, and adaptive governance. Ecology and Society 15(4):29. http://dx.doi.org/10.5751/ ES-03798-150429

Termeer, C. J. A. M., A. Dewulf, H. van Rijswick, A. van Buuren, D. Huitema, S. Meijerink, T. Rayner, and M. Wiering. 2011. The regional governance of climate adaptation: a framework for developing legitimate, effective, and resilient governance arrangements. Climate Law 2(2):159-179.

Thornton, P. K., J. van de Steeg, A. Notenbaert, and M. Herrero. 2009. The impacts of climate change on livestock and livestock systems in developing countries: a review of what we know and what we need to know. Agricultural Systems 101(3):113-127. http://dx.doi.org/10.1016/j.agsy.2009.05.002

Tyus, H. M. 2011. Ecology and conservation of fishes. CRC, Boca Raton, Florida, USA.

Vervoort, J. M., P. K. Thornton, P. Kristjanson, W. Förch, P. J. Ericksen, K. Kok, J. S. I. Ingram, M. Herrero, A. Palazzo, A. E. S. Helfgott, A. Wilkinson, P. Havlík, D. Mason-D'Croz, and C. Jost. 2014. Challenges to scenario-guided adaptive action on food security under climate change. Global Environmental Change 28:383-394. http://dx.doi.org/10.1016/j.gloenvcha.2014.03.001

Wang, P., P. Pattison, and G. Robins. 2013a. Exponential random graph model specifications for bipartite networks: a dependence hierarchy. Social Networks 35(2):211-222. http://dx.doi. org/10.1016/j.socnet.2011.12.004

Wang, P., G. Robins, P. Pattison, and E. Lazega. $2013 b$. Exponential random graph models for multilevel networks. Social Networks 35(1):96-115. http://dx.doi.org/10.1016/j.socnet.2013.01.004

Williamson, O. E. 1981. The economics of organization: the transaction cost approach. American Journal of Sociology 87 (3):548-577. http://dx.doi.org/10.1086/227496

Woolcock, M., and D. Narayan. 2000. Social capital: implications for development theory, research, and policy. World Bank Research Observer 15(2):225-249. http://dx.doi.org/10.1093/ wbro/15.2.225

Young, O. R. 2002. The institutional dimensions of environmental change: fit, interplay, and scale. MIT Press, Cambridge, Massachusetts, USA. 
Appendix 1. Interpretation of control variable and structural parameter estimates from exponential random graph models

All analyses were conducted using the "statnet" suite of packages (Handcock et al. 2008) in R version 3.3 (R Core Team 2016). In the description and interpretation of each parameter below, specific statnet terms are identified as they appear in the model formula. Estimation followed a burn-in of 50,000 proposals; the sample size and interval were both set to 6,000 .

The parameter COLLABORATIVE CLOSURE (modeled using the statnet term "edgecov") is a generic variant of the substructures depicted in panels $C$ and D of Figure 1; it does not account for the levels at which actors and forums operate. In the full model, which includes XL-UP VIA COLLABORATIVE CLOSURE and XL-DOWN VIA COLLABORATIVE CLOSURE, this parameter captures the propensity of within-level actor-forum linkages that feature collaborative closure, while in the baseline model, the parameter indicates the likelihood of within- or crosslevel forum participation conditional on collaborative closure. In both models, the parameter is positive and significant, indicating that collaborative closure increases the likelihood forum participation (in the baseline model) as well as the likelihood of participation in forums at actors' own levels of operation (in the full model).

The INFLUENTIAL PARTICIPANTS ("edgecov") is similar to COLLABORATIVE CLOSURE in that it is a generic variant of the substructures depicted in panels E and F of Figure 1 ; it does not account for the levels at which actors and forums operate. The parameter estimate indicates that joint participation of influential actors does not significantly increase the likelihood of within-level actor-forum linkages.

The parameter ACTOR STAFF SIZE ("b1 factor") is binary and takes the value of "large" for actors with more than 25 staff members (the median staff size for our data), and "small" otherwise. We included the parameter to help control for the effect of actor capacity on forum participation. The parameter is not significant, indicating that actors with more than 25 staff members are not significantly more likely to participate in a given forum compared with actors with 25 or fewer staff members.

The parameter ACTOR COLLABORATIVE ACTIVITY ("blcov") accounts for out-degree centrality in actors' collaborative relationships with one another. The survey prompted respondents to identify these relationships through the question: "Please list the organizations your organization has collaborated with in the context of climate change adaptation in the past year." Using these data, we constructed a network of actor-actor collaborative relationships. This parameter was not significant. However, the ACTOR COLLABORATIVE POPULARITY ("blcov") parameter, which measures in-degree centrality, was positive and significant, indicating that actors nominated as collaborators by a larger number of other actors tend to participate in more policy forums. 
FORUM LEVEL ("b2factor”) accounts for the popularity of forums that operate at levels lower than the regional level, compared to forums operating at the regional level or at higher levels. This parameter did not have a significant effect. Because the cross-level parameters (XL-UP and XL-DOWN) are binary and measure linkages between two levels, it is not possible to include a corresponding "actor level" parameter without eliminating the FORUM LEVEL parameter (i.e., there would be no reference category).

The EDGES ("edges") parameter provides a reference measure of the likelihood that a given actor participates in a given forum. This parameter is commonly described as analogous to the intercept term in a logit model.

The final two terms account for more complex network structures. Specifically, the GW (ACTOR) DEGREE ("gwb1degree") and GW (FORUM) DEGREE ("gwb2degree") parameters measure the degree distribution of both modes (i.e., actors and forums) of the network. In network terminology, "degree" is the sum of ties on each actor/forum node. In our context, an actor of degree 3 participates in 3 forums. A forum of degree 10 has 10 actors that participate in it. For each of the two modes in the network, the corresponding parameter indicates the extent to which each tie decreases the likelihood of an additional tie, and the strength of this effect itself decreases geometrically according to a decay parameter $\theta_{s}$. For example, the negative $\mathrm{GW}$ (FORUM) DEGREE parameter estimate indicates that actors tend to participate in forums that have relatively many other participants, rather than few. The GW (ACTOR) DEGREE parameter is positive, but not significant. The decay parameter $\theta_{s}$, which controls the geometric weighting of the degree count statistic, was set at 2.5 for both GW (FORUM) DEGREE and GW (ACTOR) DEGREE to optimize model fit (Figure A2.1).

\section{References:}

Handcock, M. S., D. R. Hunter, C. T. Butts, S. M. Goodreau, and M. Morris. 2008. statnet: Software Tools for the Representation, Visualization, Analysis and Simulation of Network Data. Journal of statistical software 24(1):1548-7660.

R Core Team. 2016. R: A language and environment for statistical computing. R Foundation for Statistical Computing, Vienna, Austria. 
Appendix 2. Model fit

We evaluated model fit by comparing statistics of our empirical network to distributions of corresponding statistics drawn from simulations of networks using model parameters. When values of empirical statistics are not statistically different from the expected values of corresponding statistics from simulated networks, we infer good model fit. Figure A2.1 indicates good model fit, both in terms of the parameters included in the model (Panel A) as well as network structures not included in the model, although the model slightly overestimated higher geodesic distances (Panel B).

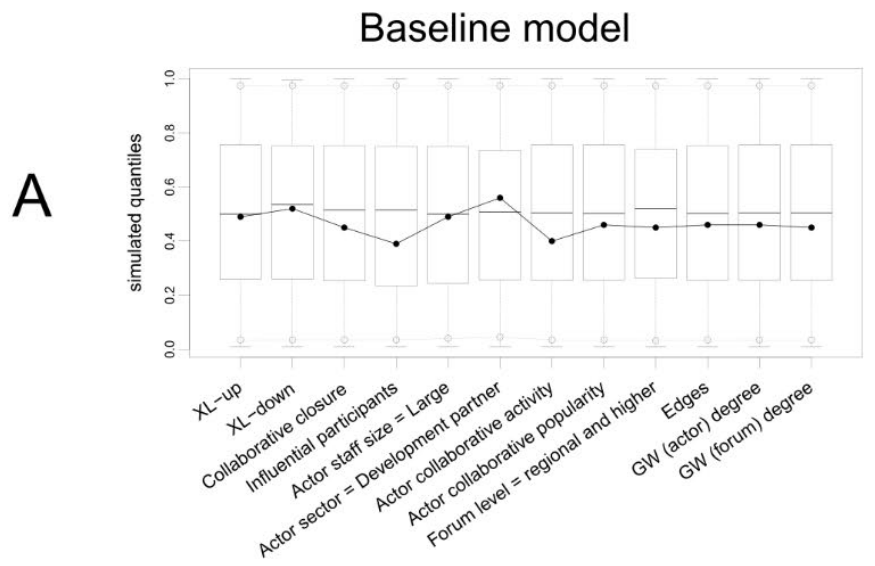

Baseline model
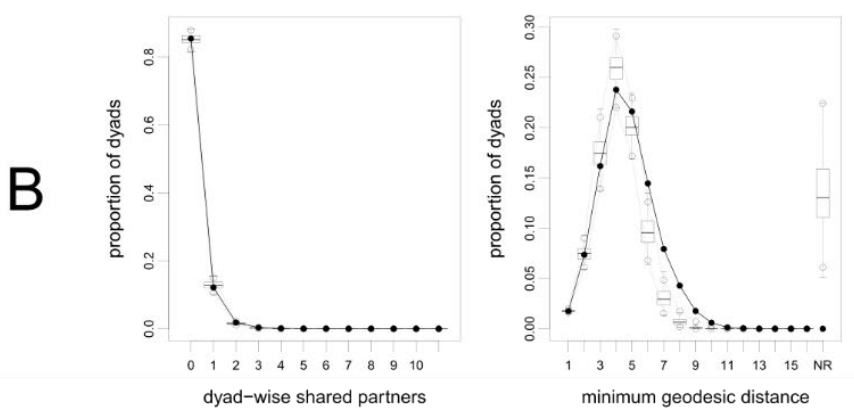

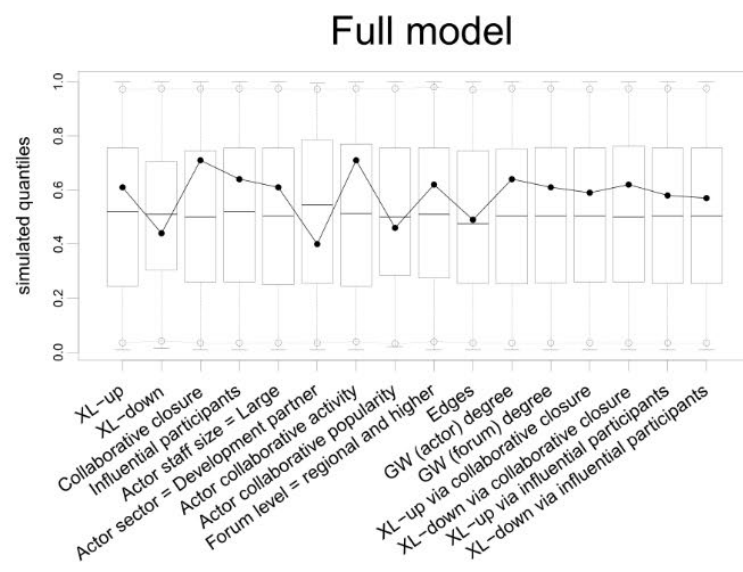

Full model
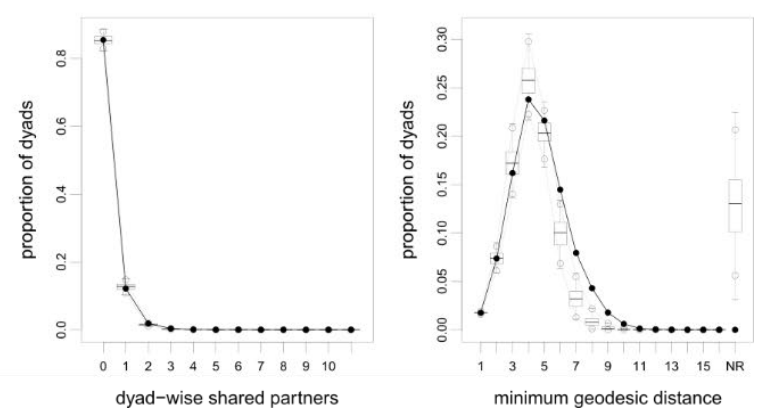

Figure A2.1 Goodness of fit of the exponential random graph models. In each plot, boxplots indicate statistics drawn from networks simulated using the model parameters, while the thick black line represents corresponding statistics from the observed network. 